NBER WORKING PAPER SERIES

\title{
ANTICIPATED PROTECTIONIST POLICIES, REAL EXCHANGE RATES \\ AND THE CURRENT ACCOUNT
}

Sebastian Edwards

Working Paper No. 2214

\section{NATIONAL BUREAU OF ECONOMIC RESEARCH 1050 Massachusetts Avenue \\ Cambridge, MA 02138 \\ April 1987}

I have benefited from comments by Guido Tabellini, Ken Froot, Arye Hillman, Ed Leamer, Pat Conway, Stan Black, and the participants of seminars at the University of Pennsylvania, the University of North Carolina, and UCLA. Discussions with Max Cordon and Richard Cantor have been very helpful. This research was supported by the National Science Foundation (Grant NSF 84-19932). The research reported here is part of the NBER's research program in International Studies. Any opinions expressed are those of the author and not those of the National Bureau of Economic Research. 


\section{Anticipated Protectionist Policies, Real Exchange Rates and the Current Account}

\section{ABSTRACT}

In this paper a general equilibrium intertemporal model, with optimizing consumers and producers, is developed to analyze how the anticipation of future import tariffs affects real exchange rates and the current account. The model is completely real, and considers a small open economy that produces and consumes three goods each period. It is shown that, without imposing rigidities or adjustment costs, interesting paths for the equilibrium real exchange rate can be generated. In particular "equilibrium overshooting" can be observed. Precise conditions under which an anticipated future import tariff will worsen the current account in period 1 are derived. Several ways in which the model can be extended are also discussed in detail. The results obtained from this model have important implications for the analysis of real exchange rate misalignment and overvaluation.

Sebastian Edwards Department of Economics University of California, Los Angeles Los Angeles, CA 90024

(213) $825-5304$ 
The growing U.S. external imbalance of the last few years has generated protectionist sentiments in a number of quarters. As a result, talks of new trade legislation that would impose higher import tariffs have become quite common. More recently, there has also been a growing concern regarding the behavior of the real value of the dollar. In particular a number of observers have argued that protectionist policies are required to halt its decline. ${ }^{1}$ Moreover, this protectionist mood has also affected a number of other countries, both industrialized and less developed.

Although international trade theorists have developed models that explain the contemporaneous effects of import tariffs on the trade and current accounts, there has been little work on how the anticipation of future import tariff will affect today's current account. ${ }^{2}$ However, this is an important issue, since usually the enactment of restrictive commercial policies is preceded by long discussions and parliamentary debates. In other cases the public's anticipation of future tariffs are not materialized. Nevertheless, the sole fact that some restrictive legislation was expected may affect today's current account, as well as the path of equilibrium real exchange rates.

The purpose of this paper is to develop an optimizing general equilibrium model of a real economy to investigate the way in which anticipated future import tariffs affect the path of equilibrium real exchange rates and the current account balance. The model is general enough, however, to analyze the effects of other disturbances such as permanent tariffs and terms of trade shocks. The model presented here considers the case of a small open economy where optimizing firms and consumers produce and consume three goods - importables, exportables, and 
nontradables. Foreign borrowing is allowed, and the only constraint faced by the nationals of this country is that the discounted value of the sum of the current account balances equals zero. There is no uncertainty, and agents have perfect foresight. The model is completely real and is solved using duality theory.

The paper is organized as follows. In Section I an intertemporal general equilibrium model of a (small) real economy with optimizing consumers and producers is developed. Here the concept of equilibrium RER in an intertemporal setting is discussed, and the modeling strategy is set forward. Section II deals with the effects of the anticipation of a future import tariff on equilibrium real exchange rates (RERs) and the current account, under the assumption that initially there are no tariffs. In Section III the impact of an anticipated hike in a previously existing tariff is analyzed. Section IV deals with extensions, while Section V contains the concluding remarks.

\section{The Mode1}

In this section a three goods-two periods model is developed in order to analyze how the anticipation of the imposition of import tariffs affects the equilibrium path of real exchange rate and the current account in the current period.

Consider the case of a small country that produces and consumes three goods - - importables (M) exportables (X) and nontradables (N). There are two periods - the present (period 1) and the future (period 2) -. and foreign borrowing and lending is allowed at the exogenously given world interest rate $r^{*}$. The country faces an intertemporal budget constraint that states that the discounted sum of the current account balances is zero. 
There are a large number of producers and (identical) consumers, so that perfect competition prevails. Consumers maximize utility subject to their intertemporal budget constraint, whereas firms maximize profits in each period, subject to existing technology and availability of factors of production. In order to simplify the exposition it is assumed that there is no investment (see, however, Section IV).

Assuming that the utility function is time separable, with each subutility function homothetic, the representative consumer problem can be stated as follows:

$$
\max w\left(U^{1}\left(C_{N}^{1}, C_{M}^{1}, C_{X}^{1}\right), U^{2}\left(C_{N}^{2}, C_{M}^{2}, C_{X}^{2}\right)\right\}
$$

subject to:

$$
C_{X}^{1}+p^{1} C_{M}^{1}+q^{1} C_{M}^{1}+\delta *\left(C_{X}^{2}+p^{2} C_{M}^{2}+q^{2} C_{N}^{2}\right) \leq \text { Wealth }
$$

where $W$ is the utility function; $U^{1}$ and $U^{2}$ are periods 1 and 2 subutility functions assumed to be homothetic; $\mathrm{C}_{\mathrm{N}}^{\mathrm{i}}, \mathrm{C}_{\mathrm{M}}^{\mathbf{i}}, \mathrm{C}_{\mathrm{X}}^{\mathbf{i}}$ are consumption of $N, M$ and $X$ in period $i=1,2 ; p^{i}$ is the (domestic) price of importables relative to exportables in period $i=1,2 ; q^{i}$ is the price of nontradables relative to exportables in period $i$; and $\delta *$ is the world discount factor equal to $\left(1+r^{*}\right)^{-1}$.

Wealth is the discounted sum of consumer's income in both periods. Income, in turn, is given in each period by three components: (1) income from labor services rendered to firms; (2) income from the renting of capital stock that consumers own to domestic firms; (3) and income obtained from government transfers. These, in turn, correspond to the proceeds from import tariffs which the government hands back to the public. In this model, then, as in most of the international trade literature, the government plays no active role besides imposing import tariffs, and 
handling their proceeds back to households in a nondistortionary way. ${ }^{3}$

Given the nature of preferences, the consumer optimization process takes place in two stages. First, the consumer decides how to allocate his(her) wealth across periods. Second, he(she) decides how to distribute each period (optimal) expenditure across the three goods.

It is assumed that firms use conventional technology to produce $\mathrm{N}, \mathrm{X}$ and M. There are three factors of production - capital, labor and natural resources. Consequently, factor price equalization does not hold in either period. Producers' maximization problem can be stated in each period $i$, in the following way (where $V$ is the vector of factors of production $w$ is a vector of their rewards, and $Q_{j}^{i}$ is output of good $j$ in period $\left.i.\right)$

$$
\max \operatorname{Profits}=\left(\mathrm{p}^{i} Q_{M}^{i}+q^{i} Q_{N}^{i}+Q_{X}^{i}\right)-w^{i} v^{i}
$$

subject to plausible technology.

In this small open economy the price of exportables is given from abroad and the price of importables is in each period equal to the international price of this type of goods $\left(p^{* i}\right.$ ) plus the (specific) import tariff $\left(\tau^{i}\right):$

$$
\mathrm{p}^{1}=\mathrm{p}^{* 1}+r^{1} ; \quad \mathrm{p}^{2}-\mathrm{p}^{* 2}+r^{2}
$$

The simultaneous solutions of the consumers and producers optimization problems, plus the requirement that the nontradable market clears every period, and the full employment conditions will determine the equilibrium path of nontradable prices, equilibrium real exchange rates in both periods, quantities produced and consumed of $X, M$ and $N$, the current account, and factors rewards. A very convenient way of characterizing this country's full equilibrium is by using duality theory. ${ }^{4}$ Equations (4) through (9) succinctly summarize the internal and external equilibrium conditions for 
this optimizing economy. Superscripts refer to periods (i.e., $\mathrm{R}^{2}$ is the revenue function in period 2); subscripts refer to partial derivatives with respect to that variable (i.e., $R_{1}^{1}$ is the partial derivative of period l's revenue function relative to $q_{1}$ (the price of nontradables in period 1); $\mathrm{R}^{2} \mathrm{q}^{2} \mathrm{p}^{2}$ is the second derivative of $\mathrm{R}^{2}$ with respect to $\mathrm{q}^{2}$ and $\mathrm{p}^{2}$ ). The price of exportable is taken as the numeraire:

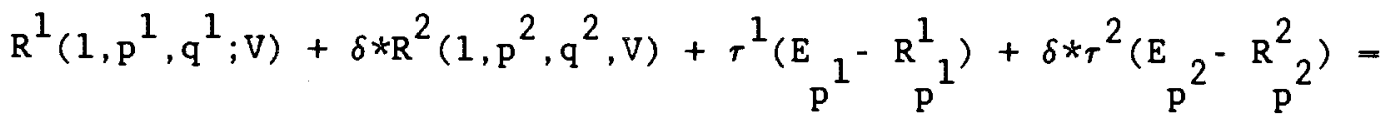

$$
\begin{aligned}
& \mathrm{E}\left[\pi^{1}\left(1, \mathrm{p}^{1}, \mathrm{q}^{1}\right), \delta * \pi^{2}\left(1, \mathrm{p}^{2}, \mathrm{q}^{2}\right), \mathrm{W}\right] \\
& \mathrm{R}^{1}{ }^{1}=\mathrm{q}^{1} \\
& \mathrm{R}^{2} \mathrm{q}^{2}=\mathrm{q}^{2} \\
& \mathrm{p}^{1}=\mathrm{p}^{1 *}+\tau^{1} \\
& \mathrm{p}^{2}=\mathrm{p}^{2 *}+\tau^{2} \text {. } \\
& \mathrm{CA}^{1}=\mathrm{R}^{1}()+\tau^{1}\left(\mathrm{E}_{\mathrm{P}}{ }^{-} \mathrm{R}_{\mathrm{P}}^{1}\right)-\pi^{1} \mathrm{E}_{\pi^{1}}
\end{aligned}
$$

where the following notation is used:

$\mathrm{R}^{\mathrm{i}}() ; i=1,2$ Revenue function in period $i$. Its partial derivative with respect to each price is equal to the respective supply function.

$\mathrm{p}^{\mathrm{i}} ; \mathrm{i}=1,2 \quad$ Domestic relative price of imports in period $i$.

$q^{i} ; i=1,2 \quad$ Relative price of nontradables in period $i$.

$V \quad$ Vector of factors of production, assumed to be fixed.

$\tau^{i} ; i=1,2 \quad$ Specific tariffs in period $i$. 


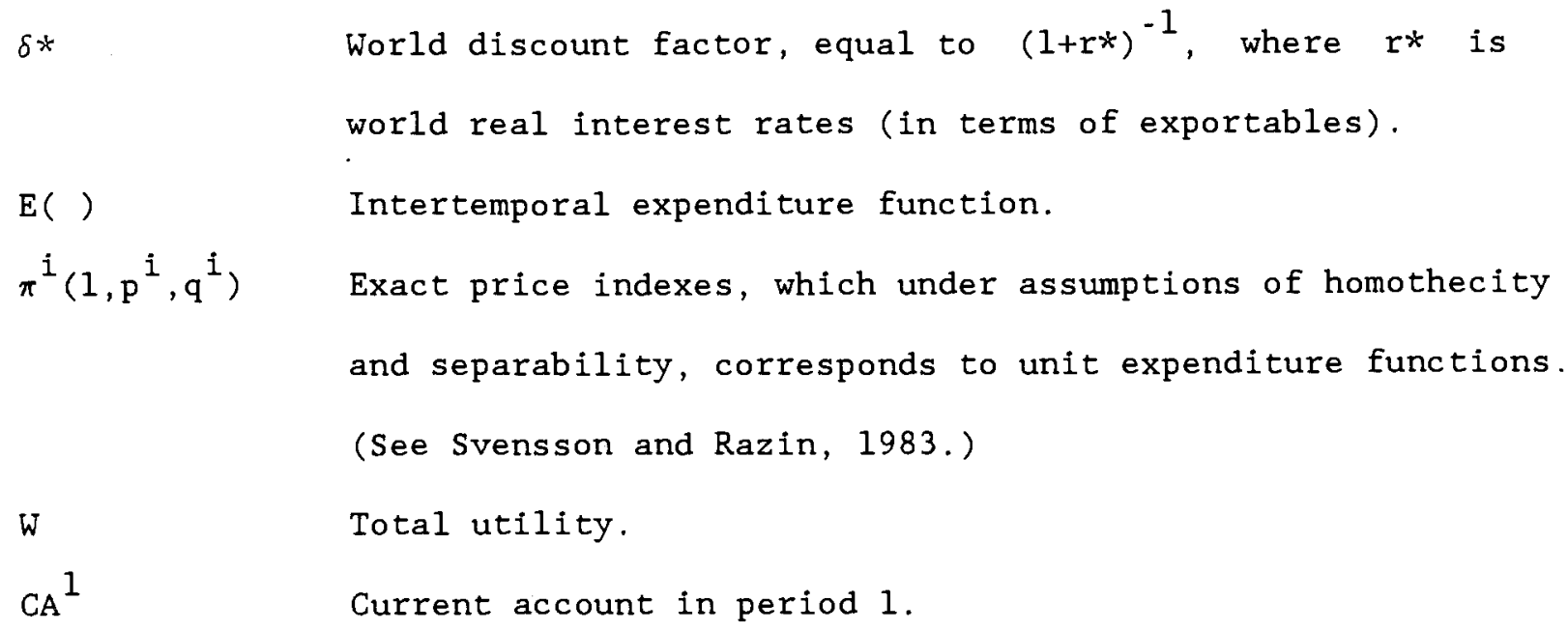

Equation (4) is the intertemporal budget constraint, and states that present value of income - generated through revenues from optimized production $R^{1}+\delta * R^{2}$, plus tariffs collection - has to equal present value of expenditure. Given the assumption of perfect access to the world capital market, the discount factor used in (1) is the world discount factor $\delta *$. Equations (5) and (6) are the equilibrium conditions for the nontradables market in periods 1 and 2 ; in each of these periods the quantity supplied of $\mathrm{N}\left(\mathrm{R}_{\mathrm{q}}^{1}\right.$ and $\left.\mathrm{R}_{2}^{2}\right)$ has to equal the quantity demanded ( $\mathrm{E}_{\mathrm{q}}$ and $\mathrm{E}_{2}$ ). Given the assumptions about preferences (separability and homothecity) the demand for $N$ in period $i$ can be written as:

$$
\mathrm{E}_{\mathrm{i}}=\mathrm{E}^{i}{ }^{\pi^{i}} \mathrm{q}^{i}
$$

Equations (7) and (8) specify the relation between domestic prices of imports, world prices of imports and tariffs (see equation (3)). Equation (9) describes the current account in period 1 as the difference between income and total expenditure in that period.

Given our assumption of time separable utility function, expenditure in periods 1 and 2 are gross substitutes. As a result all intertemporal cross

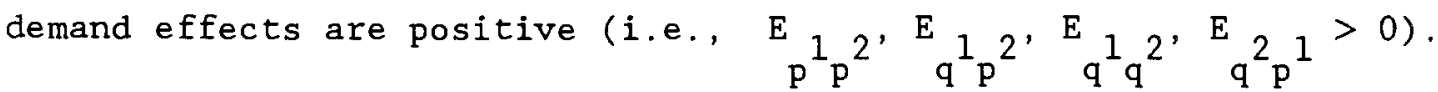


However, intratemporal cross demand effects - $E{ }^{1} q^{1}, E p^{2} q^{2}, E q^{1} p^{1}, E q^{2} p^{2}-$ can be positive or negative. The reason for this is that we have three goods in each period; any two of them can be complements in demand. On the supply side it is assumed that the three sectors compete for factors in each period; all cross price effects are thus negative $\left(R^{1} q^{1} p^{1}, R^{2} p^{2} q^{2}<0\right)$.

\section{I.1. The Concept of "Equilibrium" Real Exchange Rate}

In models with importables and exportables the definition of "the" real exchange rate becomes "tricky", since the by-now traditional concept of relative price of tradables to nontradables loses some meaning. The reason, of course, is that if there are shocks that affect the price of $X$ relative to $M$, it is not possible to talk about the Hicksian composite "tradables" anymore. In a way, in this type of model there are two RERs: the relative price of importables to nontradables $(p / q)$, and the relative price of exportables to nontradables $(1 / q)$. For this reason, and in order to simplify the exposition, in this paper we will focus on the (inverse) of real exchange rate for exports $q$. of course, once it is known how $q$ responds to changes in fundamentals, it is possible to compute, using simple algebraic manipulations, the effect of shocks on any of the traditional indexes of RER.

In the intertemporal model presented above there is not one equilibrium value of the real exchange rate, but rather a path of equilibrium RERs. Within this intertemporal framework the equilibrium (exportable) RER in a particular period is defined as the inverse of $q$ that, for given values of other variables such as world prices, technology and tariffs, equilibrates simultaneously the external and internal (i.e., nontradables) sectors. ${ }^{5}$ In terms of the model, the vector of equilibrium RERs is composed of those 
$\left(1 / q^{i}\right)$ 's that simultaneously satisfy equations (4) through (8), for given values of the other fundamental variables.

From the inspection of equations (4)-(9) it is apparent that exogenous shocks in, say, the international terms of trade, will affect the vector of equilibrium RERs through two interrelated channels. The first one is related to intratemporal effects of terms of trade shocks on resource allocation and consumption decisions. For example, as a result of a temporary worsening of the terms of trade, there will be a tendency to produce more and consume less of $M$ in that period. This, plus the income effect resulting from the worsening of the terms of trade will generate an incipient disequilibrium in the nontradables market which will have to be resolved by a change in the equilibrium q. In fact, if we assume that there is an absence of foreign borrowing these intratemporal effects will be the only relevant ones. However, with capital mobility, as in the current model, there is a second intertemporal channel through which changes in exogenous variables will affect the vector of equilibrium RERs. For example, in the case of a temporary worsening of the terms of trade, the consumption discount factor $\pi^{2} \delta * / \pi^{1}$ will be affected, altering the intertemporal allocation of consumption. 6

Equations (4)-(9) can be manipulated to find out how the vector of equilibrium RERs and the current account respond to exogenous shocks such as changes in tariffs, disturbances to the international terms of trade, international transfers, and changes in world interest rates. In order to simplify the exposition it is assumed that initially there are no import tariffs, so that $\tau^{1}=\tau^{2}=0$. In Section III, however, the more general case with positive initial tariffs is discussed. 
In Figure 1 schedules $\mathrm{H}^{1} \mathrm{H}^{1}$ and $\mathrm{H}^{2} \mathrm{H}^{2}$ summarize equilibrium in the nontradables market in periods 1 and $2 .^{7}$ Schedule $\mathrm{H}^{1} \mathrm{H}^{1}$ depicts the combination of $\mathrm{q}_{1}$ and $\mathrm{q}_{2}$ consistent with equilibrium in the nontradable goods market in period 1 . Its slope is equal to:

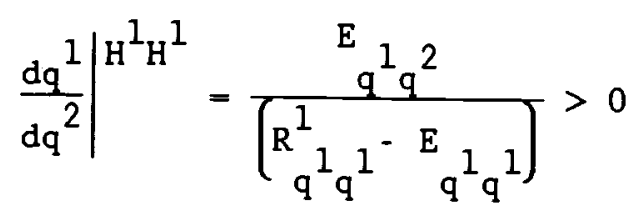

where $\mathrm{E}_{\mathrm{q}^{2} \mathrm{q}^{1}}$ is an intertemporal cross demand term that captures the reaction of the demand for $N$ in period $1\left(\mathrm{E}_{\mathrm{q}}\right)$ to an increase in nontradables prices in period 2. Given the fact that there are only two periods and the time separable nature of the utility function, expenditure in periods 1 and 2 are gross substitutes, and thus this term is positive. $\mathrm{R}^{1}{ }_{\mathrm{q}} \mathrm{q}^{1}$ is the slope of the supply curve of $\mathrm{N}$ in 1 and $E \mathrm{q}^{1} \mathrm{q}^{1}$ is the slope of the compensated demand curve. Then, $\left(\mathrm{R}^{1} \mathrm{q}_{\mathrm{q}}{ }^{1}-\mathrm{E}^{1} \mathrm{q}^{1}\right)$ is positive. The intuition behind the positive slope of $\mathrm{H}^{1} \mathrm{H}^{1}$ is the following: An increase in the price of $\mathrm{N}$ in period 2 will make consumption in that period relatively more expensive. As a result there will be a substitution away from period 2 and towards period 1 expenditure. This will put pressure on the market for $N$ in period 1 , and an incipient excess demand for $N$ in that period will develop. The reestablishment of nontradable equilibrium in period 1 will require an increase the relative price of $N$.

Schedule $\mathrm{H}^{2} \mathrm{H}^{2}$ depicts the locus of $\mathrm{q}^{1} \mathrm{q}^{2}$ compatible with nontradable market equilibrium in period 2. Its slope is positive and equal to:

$$
\left.\frac{d q^{2}}{d q^{2}}\right|^{H^{2} H^{2}}=\frac{\left(R^{2} q^{2} q^{2}-E q^{2} q^{2}\right)}{E q^{1} q^{2}}>0
$$


The intuition behind this positive slope is analogous to that of the $\mathrm{H}^{1} \mathrm{H}^{1}$ schedule: an increase in $\mathrm{q}^{1}$ will make current consumption relatively more expensive, shifting expenditure into the future. As a result there will be a pressure on $\mathrm{q}^{2}$, which will have to increase to reestablish equilibrium. Stability requires that the $\mathrm{H}^{2} \mathrm{H}^{2}$ schedule be steeper than the $\mathrm{H}^{1} \mathrm{H}^{1}$ curve (see Appendix).

The intersection of $\mathrm{H}^{1} \mathrm{H}^{1}$ and $\mathrm{H}^{2} \mathrm{H}^{2}$ at $\mathrm{A}$ characterize the (initial) relative prices of the nontradable goods market in periods 1 and 2 ( $\left.\tilde{q}^{1}, \tilde{q}^{2}\right)$ compatible with the simultaneous attainment of intertemporal external equilibrium and internal equilibrium in both periods. In order to make the exposition clearer we have assumed that these equilibrium prices $\tilde{q}^{1}$ and $\tilde{q}^{2}$ are equal; the $45^{\circ}$ line passes through the initial equilibrium point $A .^{9}$

\section{Anticipated Future Import Tariffs: The Zero Initial Tariffs Case}

In this section we analyze how the anticipation of the future imposition of an import tariff will affect the equilibrium RERs, and period I's current account. We as sume that the initial condition is characterized by no import tariffs in either period $\left(\tau^{1}=\tau^{2}=0\right)$. In Section III we look at the more general case of positive initial tariffs.

\section{II.1. Equilibrium Real Exchange Rates}

Consider the case where, in period 1 , economic agents (correctly) expect that the government will impose an import tariff $\tau^{2}$ in period 2 . This will shift both the $\mathrm{H}^{1} \mathrm{H}^{1}$ and $\mathrm{H}^{2} \mathrm{H}^{2}$ schedules, generating a new vector of equilibrium relative prices. Let's first consider the case of $\mathrm{H}^{1} \mathrm{H}^{1}$. An anticipated import tariff in 2 means that the expected price of imports in that period will increase, making future consumption relatively more expensive. Consequently, via the intertemporal substitution effect, 
Figure 1

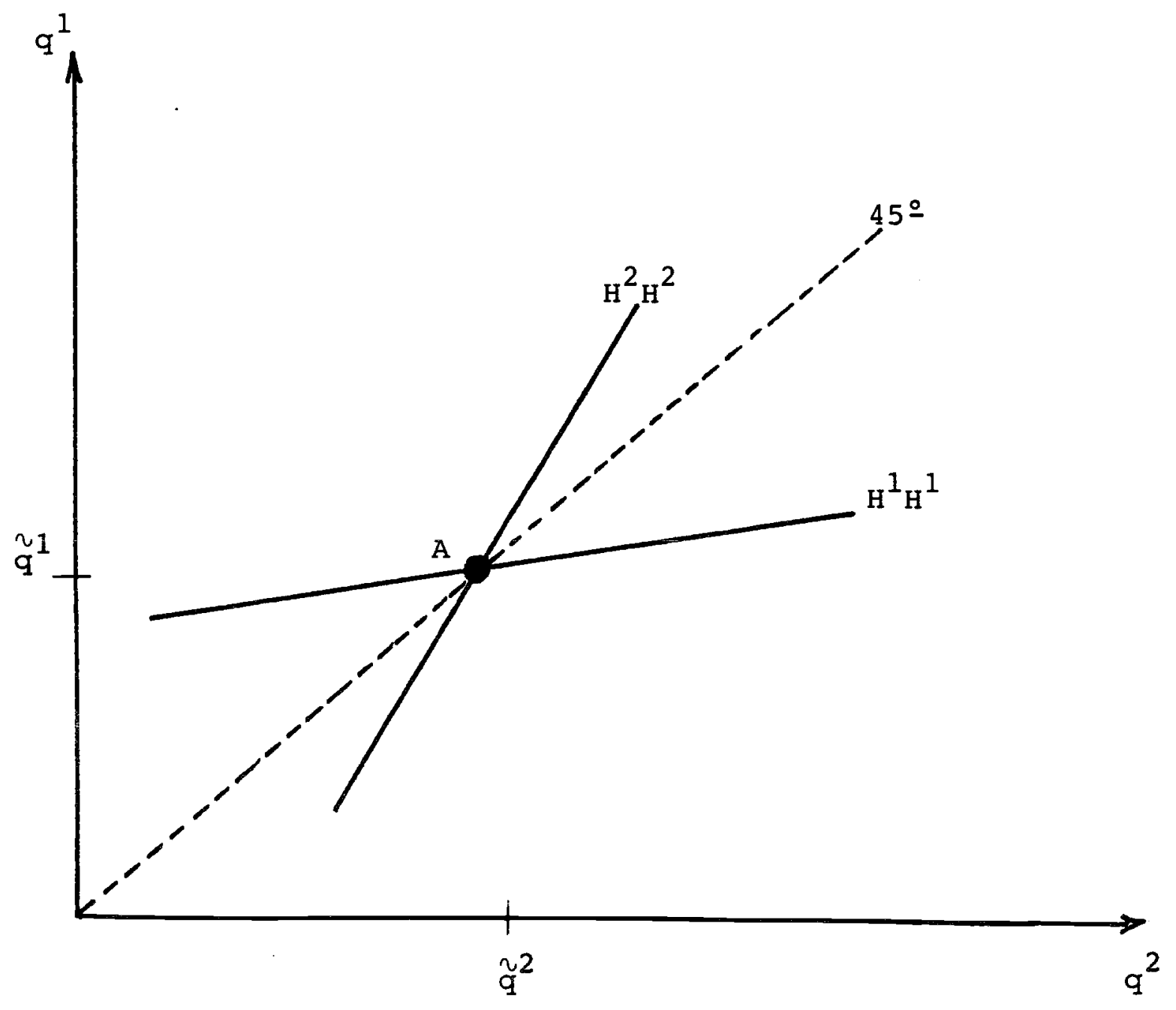


consumers will substitute expenditure away from period 2 and into period 1. This will result in an increase in the demand for all goods in period 1 , including nontradables, and in a higher $q^{1}$. Consequently the $\mathrm{H}^{1} \mathrm{H}^{1}$ curve will shift upward. From equation (5) it is possible to find the magnitude of this vertical shift:

$$
\left.\left.\left.\left.\mathrm{dq}\right|_{\mathrm{dq}} ^{1}\right|_{\mathrm{q}^{2}=0} ^{\mathrm{H}^{1} \mathrm{H}^{1}}{ }^{2} \mathrm{q}^{1} \mathrm{q}^{1}-\mathrm{E}^{1} \mathrm{q}^{1}\right)\right\} \mathrm{d} \tau^{2} .
$$

As this expression shows, this movement in the $\mathrm{H}^{1} \mathrm{H}^{1}$ curve is a reflection of the intertemporal degree of substitutability in consumption: it will be greater or smaller depending on whether $\mathrm{E}_{\mathrm{q}} \mathrm{p}^{2}$ is large or small. In the extreme case of no intertemporal substitution $\left(\mathrm{E}_{\mathrm{q}}{ }^{1} \mathrm{p}^{2}=0\right)$, the $\mathrm{H}^{1} \mathrm{H}^{1}$ schedule will be horizontal, and will not shift as a result of expected future tariffs.

The imposition of an (anticipated) import tariff in period 2 will also affect the $\mathrm{H}^{2} \mathrm{H}^{2}$ schedule. In this case, however, in addition to the intertemporal effect already discussed, there will also be an intratemporal effect related to the change in relative prices in period 2 . Since the expected teriff will make future consumption more expensive, the intertemporal effect will generate forces towards a reduction in $q^{2}$, and a leftward movement of $\mathrm{H}^{2} \mathrm{H}^{2}$. The intratemporal effect, on the other hand, can either reinforce or tend to offset those forces. The higher domestic price of imports in period 2 will reduce the quantity demanded of $M$ in that period. Depending on whether importables and nontradables are gross substitutes or complements in consumption, in that period, the quantity demanded of $N$ will increase or decline. If $M$ and $N$ are complements, $\left(\mathrm{E}_{\mathrm{q}} \mathrm{p}^{2}<0\right)$ the higher tariff will reduce the demand for $\mathrm{N}$ in period 2 , 
and the $\mathrm{H}^{2} \mathrm{H}^{2}$ schedule may shift to the left. If, however, $N$ and $M$ are gross substitutes, the imposition of the period 2 tariff will increase the demand for $N$. In this case the $\mathrm{H}^{2} \mathrm{H}^{2}$ curve will shift to the right. Formally, the horizontal shift of $\mathrm{H}^{2} \mathrm{H}^{2}$ can be obtained from equation (6):

$$
\left.\mathrm{dq}^{2}\right|_{\mathrm{dq} \mathrm{H}^{1}=0} ^{\mathrm{H}^{2} \mathrm{H}^{2}}=\frac{\left(E \mathrm{q}^{2} \mathrm{p}^{2}-\mathrm{R}^{2} \mathrm{q}^{2} \mathrm{p}^{2}\right.}{\left.\mathrm{R}_{\mathrm{q}^{2} \mathrm{q}^{2}-\mathrm{E} \mathrm{q}^{2} \mathrm{q}^{2}}\right)} \mathrm{d} \tau^{2} \gtrless 0 .
$$

It is clear from (13) that the indeterminacy stems from the fact that $E q^{2} p^{2}$ can be either positive or negative. A necessary condition for the $\mathrm{H}^{2} \mathrm{H}^{2}$ schedule to shift to the left is that $N$ and $M$ are complements, so that $\mathrm{p}^{2} \mathrm{q}^{2}<0$. On the other hand, a sufficient condition for the $\mathrm{H}^{2} \mathrm{H}^{2}$ to shift to the right is that ${ }_{\mathrm{P}}{ }^{2} \mathrm{q}^{2}>0$.

Figure 2 illustrates two possible new equilibria. Point A characterizes the initial equilibrium. Point $B$ corresponds to the case when $N$ and $M$ are gross substitutes and the intratemporal effect is strong enough: the new (after tariff anticipation) equilibrium schedules are $\tilde{\mathrm{H}}^{1} \tilde{\mathrm{H}}^{1}$ and $\tilde{\mathrm{H}}^{2} \tilde{\mathrm{H}}^{2}$. In this case the anticipation of an import tariff results in a higher relative price of nontradables in periods 1 and 2 . That is, the equilibrium RER appreciates in both periods, as a result of the expected tariff. Notice, however, that there is nothing in the model that tells us which of the two curves shifts by more (see below for the exact expression for $\left(\mathrm{dq}^{1} / \mathrm{d} \tau^{2}\right)$ and $\left.\left(\mathrm{dq}^{2} / \mathrm{d} \tau^{2}\right)\right)$. This gives rise to the possibility of some interesting equilibrium paths for the RERs. For example, it is possible to observe an "equilibrium overshooting", where (relative to the no-tariff case) $\tilde{q}^{1}$ increases by more than $\tilde{q}^{2}$. This would be the case if the $\mathrm{H}^{1} \mathrm{H}^{1}$ shifts to the left by more than what $\mathrm{H}^{2} \mathrm{H}^{2}$ shifts to the right. 
Figure 2

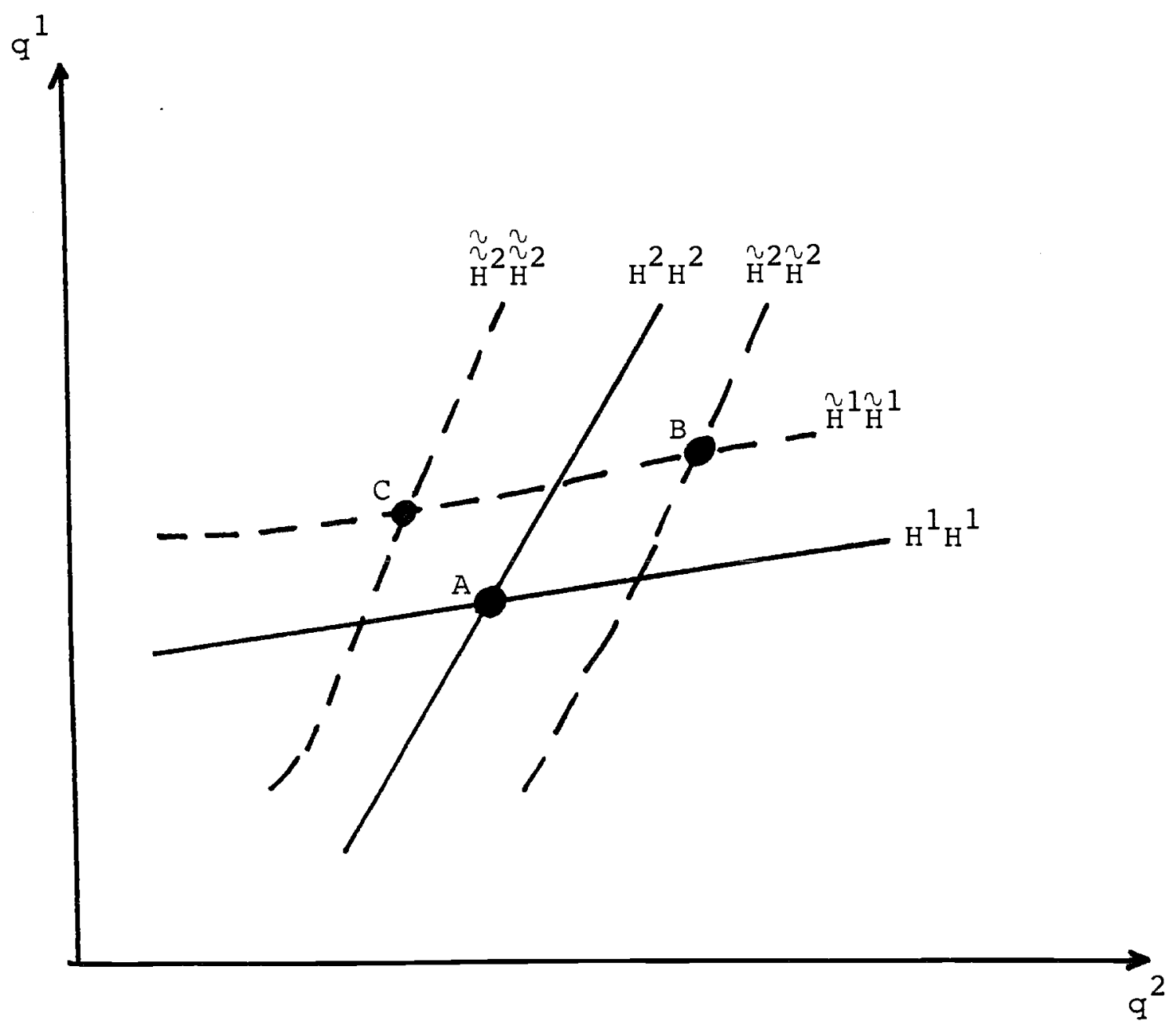


Figure 3

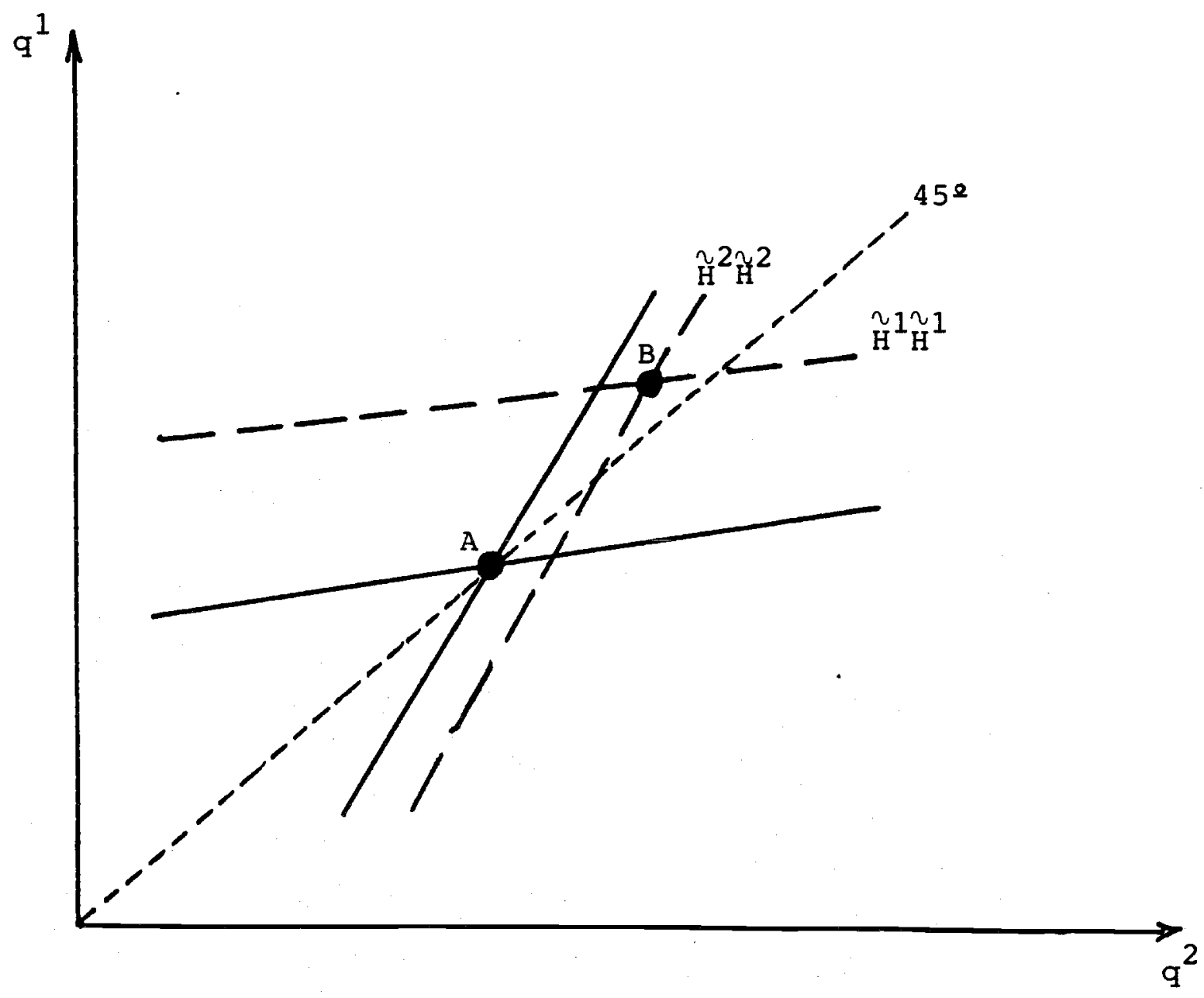


This will be the case if the new equilibrium point is above the $45^{\circ}$ line, and is illustrated in Figure 3.

Point $C$ in Figure 2 is the new equilibrium under the assumption that nontradables and importables are complements in consumption in period 2 , and that this effect dominates. In this case, as discussed, the $\mathrm{H}^{2} \mathrm{H}^{2}$ schedule will shift to the left to a position such as $\widetilde{\mathrm{H}}^{2} \widetilde{\mathrm{H}}^{2}$. A possible outcome is the one described in Figure 2 where as a result of an anticipated tariff the equilibrium path of the real exchange rate will be characterized by wide swings: it will increase in period 1, and it will decline in period 2 below its initial (pre-tariff) level. Although this path is clearly characterized by equilibrium movements in each period, observers may think that the RER has moved in the "wrong direction" in period 1. Notice that this type of behavior of the RER can even happen if $M$ and $N$ are substitutes. The $\mathrm{H}^{2} \mathrm{H}^{2}$ will shift to the left if the intertemporal effect dominates.

Figure 4 provides a diagrammatical illustration of four possible paths for the real exchange rate in periods 1 and 2 as a result of the anticipation of an import tariff. In these diagrams $\tilde{q}$ is the equilibrium RER in both periods under the assumption of no tariffs, and is used as a benchmark for comparison. $\widetilde{q}^{1}$ and $\widetilde{\widetilde{q}}^{2}$ are the equilibrium relative prices in periods 1 and 2 in the anticipated tariff case. Panel (a) in Figure 3 illustrates what we have called "equilibrium overshooting" of the relative price, where in the tariff case $\mathrm{q}^{1}$ and $\mathrm{q}^{2}$ are higher than in the nontariff case, but the adjustment implies an equilibrium reduction of $q$ in period 2. By analogy, case (b) can be called "equilibrium undershooting". Here both $\tilde{\mathrm{q}}^{\prime} \mathrm{s}$ are also higher than in the non-tariff case. Now, however, the adjustment path requires an equilibrium increase of $q$ in period 2 , 
over and above the higher $\mathrm{q}$ in period 1. Panel (c) depicts the case where the equilibrium RERs move in opposite directions in each period. In period 1 there is a real appreciation, relative to the non-tariff case, while in period 2, the period when the tariff is actually imposed, there is a real depreciation. As noted, a sufficient condition for this to be the case is that $E_{p^{2} q^{2}}<0$. Finally, panel (d) is the most "traditional" case, where as a consequence of the anticipated tariff the RER appreciates by the same amount in both periods.

From equations (4), (5), (6) and (8) it is possible to formally find the equilibrium changes in $\mathrm{q}^{1}$ and $\mathrm{q}^{2}$ as a result of the anticipated import tariff:

$$
\begin{aligned}
& \frac{\mathrm{dq}}{\mathrm{d} \tau^{2}}=-\left(\frac{1}{\Delta 1}\right)\left\{\mathrm{E}_{\mathrm{q} \mathrm{p}^{2}}\left(\mathrm{R}^{2} \mathrm{q}^{2} \mathrm{q}^{2}-\mathrm{E}_{\mathrm{q}} \mathrm{q}^{2}\right)+\mathrm{E}_{\mathrm{q}} \mathrm{q}^{2}{ }^{\left(\mathrm{E}_{\mathrm{q}} \mathrm{q}^{2} \mathrm{2}^{-} \mathrm{R}^{2} \mathrm{q}^{2} \mathrm{p}^{2}\right)}\right\}
\end{aligned}
$$

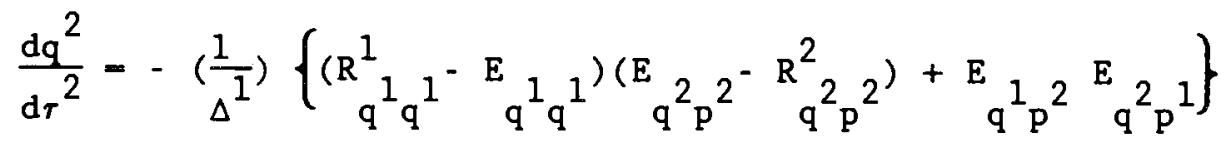

where ${ }^{10}$

$$
\Delta^{1}=-\left[\left(R_{q^{1} q^{1}}^{1}-E q^{1} q^{1}\right]\left(R_{q^{2} a^{2}}{ }^{-E} q^{2} q^{2}\right)-E q^{2} q^{1}{ }^{2} q^{1}{ }^{2}\right]<0
$$

Equations (14) and (15) formally confirm the preceding diagrammatic analysis, showing that in this three good-two period model, an anticipated import tariff can, in principle, generate interesting dynamic paths of the equilibrium real exchange rate under a pure real equilibrium analysis.

\section{II.2. The Current Account}

From equation (9) an expression for the change of the current account balance in period 1 , as a result of the anticipation of a tariff in 2 , can be obtained: 11 
Figure 4

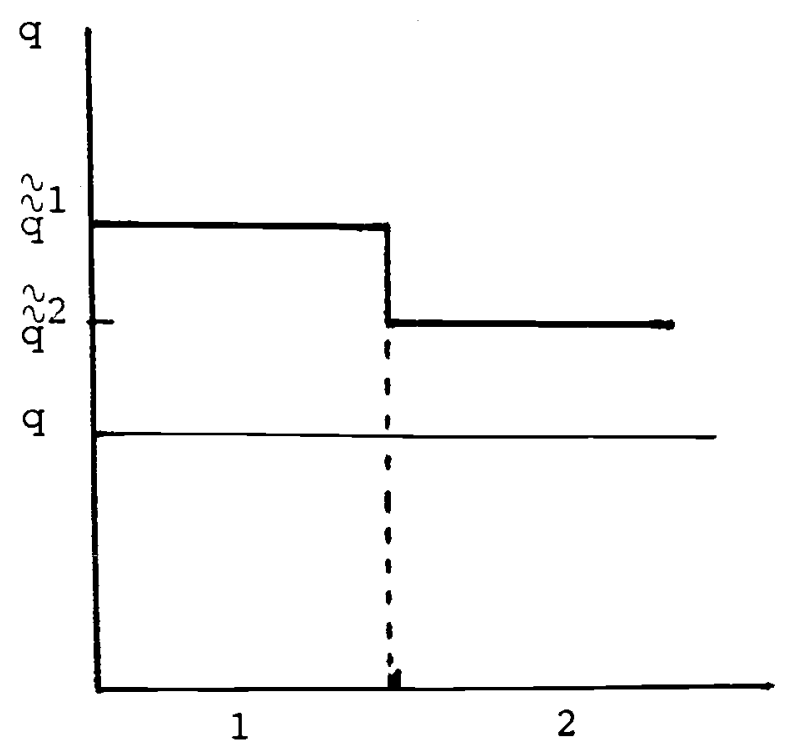

(a)

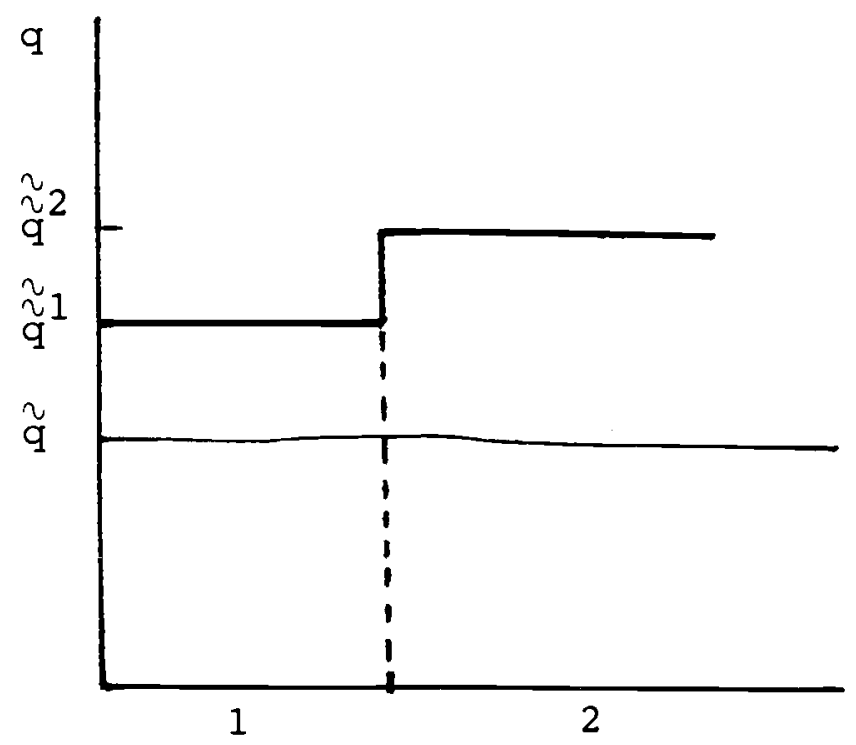

(b)

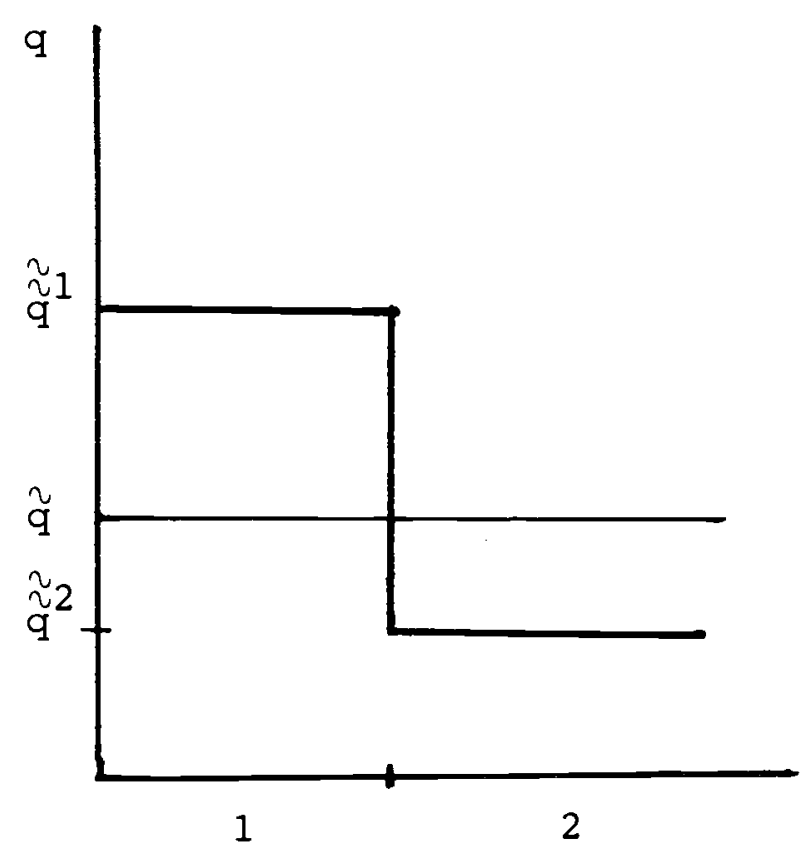

(c)

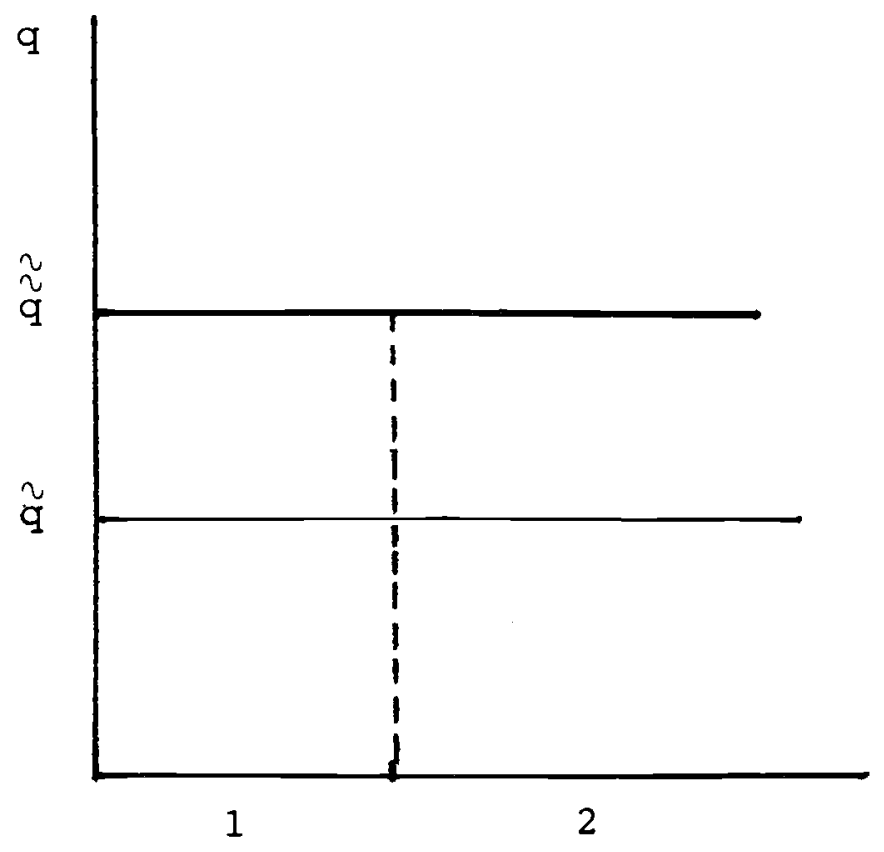

(d) 


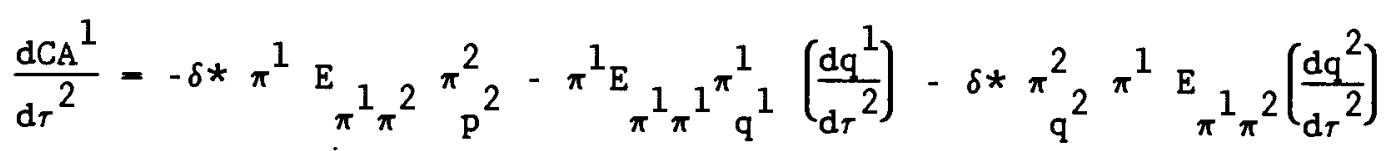

The presence of an $E_{\pi_{i}} j$ term in every one of the RHS terms of equation (16) clearly highlights the fact that the anticipated imposition of a future tariff will affect the current account via intertemporal channels. The first term in the RHS of equation (16) is negative and captures the direct effect of the anticipation of a tariff in period 2 on the current account in period 1 . The intuition for this negative effect is straightforward. The anticipated higher period two tariff makes period 2 consumption relatively more expensive, and as a result of this the public substitutes consumption away from period 2 into period 1 , generating a worsening of the current account balance in period 1 . The magnitude of this effect will depend both on the intertemporal substitution effect $E \pi^{1} \pi^{2}$ and on the initial share of imports on period 2 expenditure $\pi^{2}{ }^{2}$.

The second and third terms on the RHS of equation (16) are indirect effects, that operate via changes in periods 1 and 2 equilibrium real exchange rates. Since, as was established above, the signs of $\left(d q^{1} / d \tau^{2}\right)$ and $\left(\mathrm{dq}{ }^{2} / \mathrm{d} \tau^{2}\right)$ cannot be determined a priori, the signs of these two terms in (16) are generally undetermined, as will be the sign of equation (16) as a whole. However, the interpretation of these two indirect terms is quite straightforward within the intertemporal framework of the current model. If the anticipated tariff results in an equilibrium real appreciation in period 1, $\left(\mathrm{dq}{ }^{1} / \mathrm{d} \tau^{2}\right)>0$, there will be an offsetting force towards a current account improvement. The reasoning is again simple. If the anticipated tariff results in a higher equilibrium price of nontradables in period 1 (i.e., in a real appreciation in 1), there will be substitution away from period 1 expenditure, generating an improvement in the current account in 
that period. The third term on the RHS relates the change in period 2's RER to period l's current account. If as a consequence of the anticipated tariff $q^{2}$ increases (see equation (15) above for the conditions under which this will take place), there will be a tendency to substitute expenditure away from period 2 into period 1 , generating forces that will tend to worsen period l's current account. On the contrary, if as a result of the anticipated tariff there is a real depreciation in period 2 , $\left(\mathrm{dq}^{2} / \mathrm{d} \tau^{2}\right)<0$, expenditure will go down in period 1 with the consequence improvement of the current account.

The total effect of the anticipation of an import tariff on period 1's current account will depend on the strength of the intertemporal price effects, initial expenditure on income and nontradables, and on the effects of the tariff on the RER vector. This result contrasts with the traditional static view where the conditions for tariffs improving the current account are related to imports and exports elasticities within each period. An important result of this analysis is that, under very plausible conditions, it is possible that the sole anticipation of the enactment of future protectionist policies will worsen today's current account. Moreover, it is possible to simultaneously observe a worsening of the current account and a real depreciation; a combination that would puzzle a number of observers, including the media.

\section{The Case of Positive Initial Tariffs}

If initially there are positive tariffs, the anticipation of a future hike in tariffs will generate a first order negative income effect in period 2. ${ }^{12}$ Households will try to smooth consumption through time, and the effect on consumption of this negative income effect will be spread across periods. 
This income effect will result in a drop in demand for nontradables in periods 1 and 2 and will generate downward pressure on the relative price of $N$ in both periods. This is because the reduction of real income associated with the period 2 tariff hike will provoke an incipient excess supply of nontradables in both periods. The reestablishment of equilibrium will require a reduction in home goods prices. The presence of this income effect will enhance the possibility of observing "interesting" dynamics in the behavior of the equilibrium RERs, such as overshooting or opposite movements :

$$
\frac{\mathrm{dq}}{\mathrm{d} \tau^{2}} \lessgtr 0 ; \quad \frac{\mathrm{dq}}{\mathrm{d} \tau^{2}} \gtrless 0 .
$$

In this case the income effect also plays a role in the reaction of the current account to the anticipation of a hike in period 2's tariffs:

$$
\begin{aligned}
& \frac{\mathrm{dCA}}{\mathrm{d} \tau^{2}}=-\delta * \pi^{1} \mathrm{E}{ }_{\pi}^{1} \pi^{2}{ }_{\mathrm{p}^{2}}{ }^{2}-\pi^{1} \mathrm{E}{ }_{\pi}^{1} \pi^{1}{ }^{2}{ }_{\mathrm{q}}^{1}\left(\frac{\mathrm{dq}}{\mathrm{d} \tau^{2}}\right) \\
& -\pi^{1} \delta * \pi_{q^{2}}^{2}{ }_{\pi}^{1} \pi^{2}\left(\frac{\mathrm{dq}^{2}}{\mathrm{~d} \tau^{2}}\right)+\mathrm{E}_{\pi}{ }^{1} \mathrm{~W}\left(\pi^{1} \pi_{\mathrm{P}}^{1}-\pi^{1}\right\} \frac{\mathrm{dW}}{\mathrm{d} \tau^{2}}
\end{aligned}
$$

where the three first terms on the RHS are the same as in equation (16) for the zero tariff case. The fourth term is related to the income effect. Since $\left(\mathrm{dW} / \mathrm{d} \tau^{2}\right)<0-$ that $^{2}$ is the future tariff reduces utility - we can see that in this case it is also possible that the anticipation of a future hike in existing import tariffs can result in a worsening of the current account in period 1 . 
IV. Temporary Tariffs, Permanent Tariffs and Other Extensions

The model developed above can be easily used to analyze the effects of temporary and permanent tariffs on the path of equilibrium RERs and on the current account. In particular, the diagrammatic analysis of Section II can handle both of these cases. In the case of temporary tariffs (i.e., a period 1 tariff only), it is easy to show that, once again, "equilibrium overshooting" can result where the initial equilibrium relative price of $N$ $\left(\mathrm{q}^{1}\right)$ increases - - in relation to the nontariff benchmark case - - by more than the equilibrium price of $\mathrm{N}$ in period 2. In the case of the imposition of a temporary tariff in period 1 only, the $\mathrm{H}^{2} \mathrm{H}^{2}$ schedule will always shift to the right, while the $\mathrm{H}^{1} \mathrm{H}^{1}$ curve can shift either to the left or to the right. Figure 5 illustrates two alternative equilibria that can result as a consequence of temporary import tariff.

With respect to the current account, a temporary tariff can either improve or worsen that period's current account balance. The intuition behind this is analogous to the case of the anticipated tariff, discussed above. More specifically:

$$
\frac{\mathrm{dCA}^{1}}{\mathrm{~d} \tau^{1}}=\alpha\left\{1-\gamma_{1}\left(\frac{\mathrm{dq}^{1}}{\mathrm{~d} \tau^{1}}\right)-\gamma_{2}\left(\frac{\mathrm{dq}^{2}}{\mathrm{~d} \tau^{2}}\right)\right\}
$$

$$
\text { where } \begin{aligned}
\alpha & =-\pi^{1}{ }^{E}{ }^{1} \pi^{1}{ }^{1}{ }_{\mathrm{p}}^{1} ; \\
\gamma_{1} & =-\left(\pi^{1}{ }^{1}{ }^{1 / \pi^{1}} \mathrm{p}^{1}\right) \\
\gamma_{2} & =-\delta *\left(\mathrm{E} \pi^{1} \pi^{2}{ }^{/ E}{ }^{1} \pi^{1}\right)\left(\pi^{2}{ }^{2}{ }^{/ \pi^{1}} \mathrm{p}^{1}\right)
\end{aligned}
$$


Figure 5

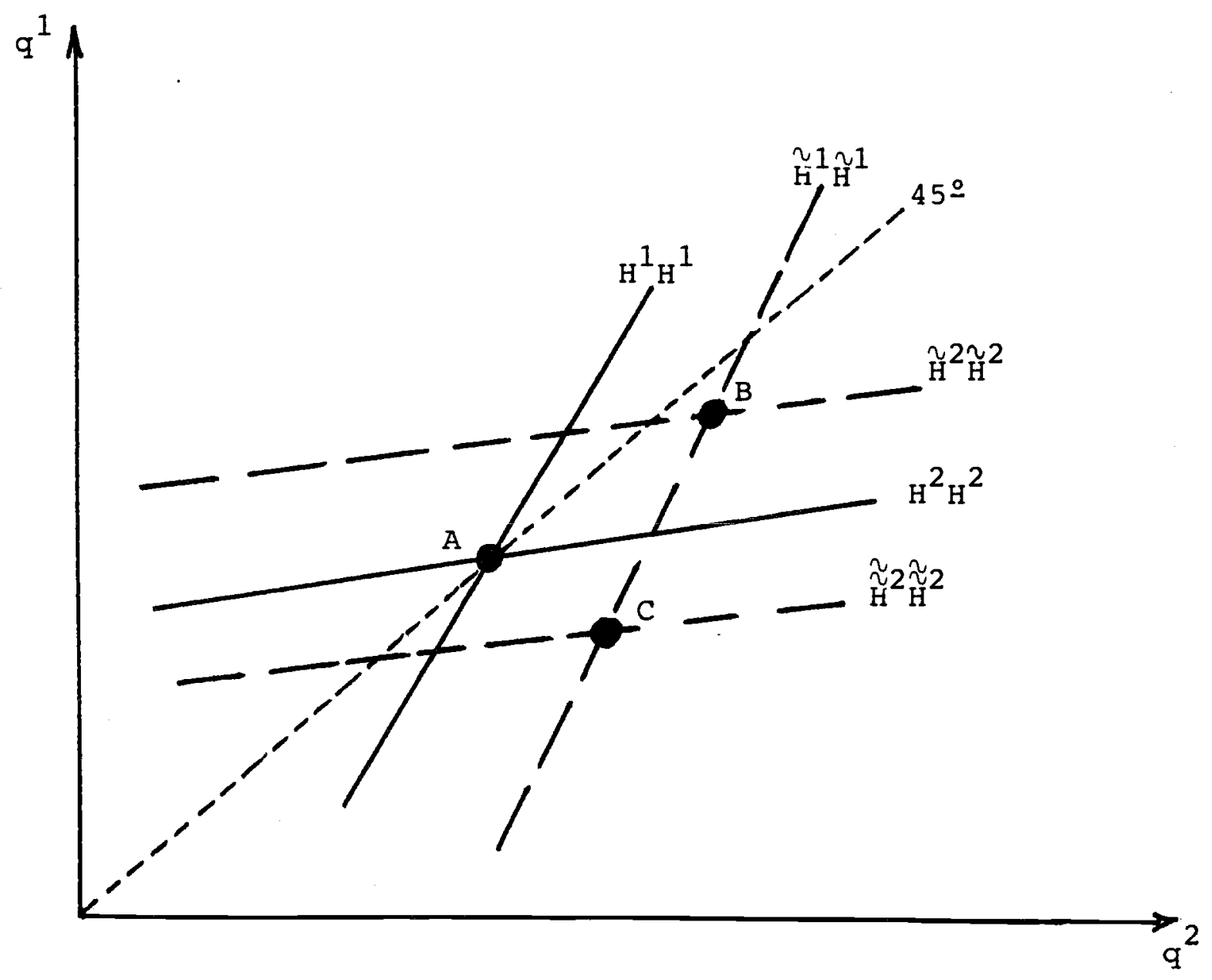


The model developed in this paper can be extended in several interesting directions. For example, the case of a large country can be easily handled by specifying a second country with a similar structure, and by adding the worldwide budget constraints. Also the case of shocks to the international terms of trade $\left(\mathrm{p}^{1 *}\right.$ and $\left.\mathrm{p}^{2 *}\right)$ can be incorporated into the discussion. In this case, however, it is not possible to ignore the income effects. Even if the initial tariffs are zero, a worsening of the terms of trade will have a first order (negative) income effect. Investment can also be introduced into the analysis. Moreover, its incorporation will not alter in a significant way the main results presented above. Once investment is added, the intertemporal budget constraint has to be altered, and an equation describing the process governing investment decisions has to be added to our system. Denoting investment by $I$, and assuming that there is time to build, the intertemporal budget constraint becomes:

$$
\begin{aligned}
& R^{1}\left(1, q^{1}, p^{1} ; K^{1}, v^{1}\right)+\delta * R^{2}\left(1, p^{2}, q^{2} ; K^{1}+I, v^{1}\right) \\
& +\tau^{1}\left(\mathrm{E}_{\mathrm{p}} \mathrm{P}_{\mathrm{p}}-\mathrm{R}^{1}\right)+\delta * \tau^{2}\left(\mathrm{E}_{\mathrm{p}}{ }^{-} \mathrm{R}_{\mathrm{p}}^{2}\right)-\mathrm{I}= \\
& E\left[\pi^{1}\left(1, p^{1}, q^{1}\right), \delta * \pi^{2}\left(1, p^{2}, q^{2}\right), W\right]
\end{aligned}
$$

Further assuming that investment decisions are governed by the condition that in equilibrium Tobin's "q" equals 1 , and that investment goods correspond to the numeraire good, the investment equation is:

$$
\delta * \mathrm{R}_{\mathrm{K}}^{2}=1
$$

The manipulation of (20) and (21) and the two conditions for equilibrium in the nontraded goods market in period 1 and 2 will now yield the corresponding expressions for changes in the RERs and the capital account. Once investment is added into the analysis the capital stock in period 2 becomes 
an endogenous variable. More specifically, it is possible to relate additions to the capital stock (dK) to anticipated changes in tariffs and to real exchange rate changes:

$$
\left(\frac{\mathrm{dK}}{\mathrm{d} \tau^{2}}\right)=-\left(\frac{\mathrm{Kp}^{2}}{\mathrm{R}_{\mathrm{KK}}^{2}}\right)-\left(\frac{\mathrm{Kq}^{2}}{\mathrm{R}_{\mathrm{KK}}^{2}}\right)\left(\frac{\mathrm{dq}^{2}}{\mathrm{~d} \tau^{2}}\right)
$$

where $\mathrm{R}_{\mathrm{KK}}^{2}<0$ is the slope of the marginal product of capital schedule; $\mathrm{R}^{2} \mathrm{Kp}^{2}$ and $\mathrm{R}^{2} \mathrm{Kq}^{2}$ are Rybczinski terms whose signs will depend on the relative ordering of factor intensities across sectors.

\section{Concluding Remarks}

The analysis presented in this paper has shown that a fairly simple real intertemporal model of a fully optimizing economy, with no rigidity or adjustment costs, can generate a number of interesting paths for the equilibrium real exchange rate, as a response to exogenous real disturbances. This suggests that real equilibrium models may be able to explain a nontrivial fraction (but not necessarily all) of observed RER movements. For example, since terms of trade shocks are very common and quite substantial in magnitude, it is possible that in a number of countries the observed wide swings in RER are, at least in part, equilibrium movements generated by the economy's reaction to terms of trade or other structural (real) disturbances. This possibility is particularly important in light of the recent interest by politicians and policymakers in real exchange rate "disequilibrium".

In fact, in the last two years or so policy analyses have increasingly focused on issues related to real exchange rate disequilibrium, and some proposals aimed at actively intervening in the exchange market in orde 
reduce real exchange rate "misalignment" have been discussed. These proposals, however, would only make sense if recent RER movements in fact represent a disequilibrium phenomenon, where the actual RER exhibits sustained departures from its equilibrium value. If, on the other hand, this is not the case, and observed RER changes respond to "fundamentals," intervention could have counterproductive effects. It would seem, then, that in order to fully understand RER behavior, and to propose policy actions, it is first necessary to have a fully articulated theory on how the equilibrium value of this relative price responds to different (real) disturbances. Most of the recent exchange rates research, however, has focused on nominal exchange rate determination, tending to ignore real aspects of real exchange rate behavior. The model presented in this paper provides a coherent fully optimizing model that can help analyze the way the equilibrium RER reacts to these changes in "fundamentals". A next step would then be to add to this model a monetary sector as well as short term rigidities in a way such that issues related to disequilibrium and misalignment could be properly analyzed.

Another important result reported in this paper is the (likely) possibility that an anticipated tariff will worsen today's current account. This implies that if protectionism is thought of as a way to tackle current account imbalances, the sole discussion of possible import tariffs in the future will make things even worse today. 


\section{Footnotes}

${ }^{1}$ See, for example, the Wall Street Journal, February 23, 1987, p. 3.

${ }^{2}$ For a somewhat different analysis of tariffs in an intertemporal setting see Stockman and Dellas (1986).

${ }^{3}$ See, however, Edwards (1987) for a related model where the government uses tariffs proceeds to finance its own consumption.

${ }^{4}$ See Dixit and Norman (1980) for the use of duality in static trade models. Svenssen and Razin (1983) and Edwards and van Wijnbergen (1986) use duality in intertemporal models without nontradables.

${ }^{5}$ Notice that implicit in this definition is the requirement of full employment.

${ }^{6}$ Razin and Svensson (1983) derived the relation between tariff changes and the consumption discount factor. See also Svensson and Razin (1983) and Edwards and van Wijnbergen (1986).

7 This type of diagram have a long tradition in international economics. See, for example, Dornbusch (1980). See also Haaparanta and Kahkonen (1986). ${ }^{8}$ The exact expression for $\mathrm{E}_{\mathrm{q}^{1} \mathrm{q}^{2}}$ is obtained after taking the derivative of equation (10).

${ }^{9}$ The existence of intertemporal substitution in consumption (E ${ }^{1} q^{2}$ and $E \mathrm{q}^{2} \mathrm{q}^{1}$ ) is what determines the positive slopes of the $\mathrm{H}^{1} \mathrm{H}^{1}$ and $\mathrm{q}^{1} \mathrm{q}^{2} \mathrm{H}^{2}$ schedules. If, however, there was no intertemporal substitution the $\mathrm{H}^{1} \mathrm{H}^{1}$ curve would be completely horizontal, with the $\mathrm{H}^{2} \mathrm{H}^{2}$ schedule being completely vertical.

${ }^{10}$ The minus sign of $\Delta^{1}$ is a result of stability (see Appendix). ${ }^{11}$ As above we still assume that initial tariffs are equal to zero. ${ }^{12}$ The reason for this is the traditional efficiency effect of tariffs. 
APPENDIX

Stability Conditions

The dynamic behavior of nontradable prices are depicted by equations (A.1) and (A.2), where $\lambda_{1}, \lambda_{2}>0$.

$$
\begin{aligned}
& \dot{\mathrm{q}}^{1}=\lambda_{1}\left[\mathrm{E}_{\mathrm{q}}{ }^{1}-\mathrm{R}_{\mathrm{q}}^{1}\right] \\
& \dot{\mathrm{q}}^{2}=\lambda_{2}\left[\mathrm{E}_{\mathrm{q}}{ }^{2}-\mathrm{R}_{\mathrm{q}}^{2}\right]
\end{aligned}
$$

Using Taylor expansions of (A.1) and (A.2) around equilibrium prices, and dropping second and higher order terms, we obtain

$$
\left(\begin{array}{l}
\dot{\mathrm{q}}^{1} \\
\dot{\mathrm{q}}^{2}
\end{array}\right)=\left(\begin{array}{cc}
\lambda\left(\mathrm{E} \mathrm{q}^{1} \mathrm{q}^{1}-\mathrm{R}^{1} \mathrm{q}^{1} \mathrm{q}^{2}\right. & \lambda_{1} \mathrm{E}^{1} \mathrm{q}^{2} \\
\lambda_{2} \mathrm{E}_{\mathrm{q}^{2} \mathrm{q}^{1}} & \lambda_{2}\left(\mathrm{E}_{\mathrm{q}^{2} \mathrm{q}^{2}-\mathrm{R}^{2} \mathrm{q}^{2} \mathrm{q}^{2}}\right.
\end{array}\right)\left(\begin{array}{l}
\mathrm{q}^{1}-\mathrm{q}^{1 *} \\
\mathrm{q}^{2}-\mathrm{q}^{2 *}
\end{array}\right)
$$

Denoting the RHS matrix as A, stability of the system requires

$$
\begin{aligned}
& \operatorname{Det} A>0 \\
& \operatorname{tr} A<; 0
\end{aligned}
$$

This means that:

$$
\left\{\left(E_{q^{1} q^{1}}-R_{q^{1} q^{1}}\right\}\left(E_{q^{2} q^{2}}-R_{q^{2} q^{2}}\right)-E_{q^{2} q^{1} q^{1} q^{2}}\right\}>0
$$

and

$$
\left\{\left(E_{q^{1} q^{1}}-R_{q^{1} q^{1}}\right)+\left(E_{q^{2} q^{2}}-R_{q^{2} q^{2}}\right)\right\}<0
$$

These requirements can then be used to sign the determinant of the system of equations in the text. Also, it follows directly from these requirements that the $\mathrm{H}^{2} \mathrm{H}^{2}$ schedule is steeper than the $\mathrm{H}^{1} \mathrm{H}^{1}$ schedule. 


\section{References}

Aizenman, J., "Tariff Liberalization Policy and Financial Restrictions," Journal of International Economics, 19 (1985): 241-255.

Calvo, G., "Temporary Liberalization: Predetermined Exchange Rates," Journal of Political Economy (December 1986c).

Corden, W.M., Protection, Growth and Trade, Blackwell, 1985.

Dixit, A., and V. Norman, Theory of International Trade, Cambridge

University Press 1980.

Dornbusch, R., Open Economy Macroeconomics, New York: Basic Books, 1980.

Edwards, S., "Economic Liberalization and the Real Exchange Rate in

Developing Countries," paper presented at the Carlos-Diaz-Alejandro

Memorial Conference, Helsinki, August 1986.

, Real Exchange Rates, Devaluation and Adjustment (forthcoming, 1987).

Edwards, S., and S. van Wijnbergen, "The Welfare Effects of Trade and Capital Market Liberalization," International Economic Review (Feb. 1986). , "Tariffs, The Real Exchange Rate and the Terms of Trade: On Two

Popular Propositions in International Economics," Oxford Economic Papers, (forthcoming).

Frenkel, J. and A. Razin, "Fiscal Policies and Real Exchange Rates in the World Economy," NBER Working Paper N2065 (December 1986).

Haaparanta, P., and J. Kahkonen, "Liberalization of Capital Movements and

Trade: Real Appreciation, Employment and Welfare," Wider Working Paper (1986).

Laursen, S., and L. Metzler, "Flexible Exchange Rates and the Theory of Employment," Review of Economics and Statistics (November 1950). 
Obstfeld, M., "Aggregate Spending and the Terms of Trade: Is There a Laursen Metzler Effect," Quarterly Journal of Economics (May 1982).

Persson, T., and L.E.O. Svensson, "Current Account Dynamics and the Terms of Trade: Harberger-Laursen-Metzler Two Generations Later," Journal of Political Economy (Feb. 1985).

Razin, A., and L.E.O. Svenson, "Trade Taxes and the Current Account," Economics Letters, (1983).

Stockman, A., and S. Dellas, "Asset Markets, Tariffs, and Political Risk," Journal of International Economics (1986).

Svensson, L.E.O., and A. Razin, "The Terms of Trade and the Current Account:

The Harberger-Laursen-Metzler Effect," Journal of Political Economy (1983).

van Wijnbergen, S., "The Dutch Disease: A Disease After All?" Economic Journal (Mar. 1984). , "Taxation of International Capital Flows," Oxford Economic

Papers (1985). , "Capital Controls and the Real Exchange Rate," CPD WP \#1985-5̦2, World Bank 1985. , "Tariffs, Employment and the Current Account," International Economic Review, forthcoming. 